EREM 75/4

Journal of Environmental Research, Engineering and Management

Vol. 75 / No. 4 / 2019

pp. 6-17

DOI 10.5755/j01.erem.75.4.23006
Techno-economic Design of Wind Farms: A Multi-scenario

Cost-based Application

Received 2019/03

Accepted after revision 2019/12

\title{
Techno-economic Design of Wind Farms: A Multi-scenario Cost-based Application
}

\section{Maurizio Faccio}

Department of Management and Engineering, University of Padua, Vicenza, Italy

\section{Mauro Gamberi}

Department of Industrial Engineering, University of Bologna, Bologna, Italy

\section{Marco Bortolini}

Department of Industrial Engineering, University of Bologna, Bologna, Italy

\section{Mojtaba Nedaei*}

Department of Management and Engineering, University of Padua, Vicenza, Italy

*Corresponding author: mojtaba.nedaei@studenti.unipd.it

Wind is a clean source of energy which is spread over wide globe regions. This natural source of energy encourages the planners and stakeholders establishing investments towards installation of wind farms. Wind energy experts are looking through efficient alternatives for the best utilization of the wind energy. Design of wind farms is a fundamental stage of wind energy projects. This study aims to address this issue by considering wind farm design to reduce the levelized cost of the generated wind energy. In the first part of the paper, an analysis of previous research works is carried out to find the latest advancements concerning the design of the wind farm layouts. In the next step, a real application, geo-located in Iran, investigates the effect of different layouts for the wind turbines. A cost approach based on the net present value (NPV) and the levelized cost of energy (LCOE) is used. The results show the optimum positioning of the wind turbines within the site to minimize interferences among the blades maximizing the economic return on the investment.

Keywords: Wind energy, wind farm design, techno-economic evaluation, energy production.

\section{Introduction}

Nowadays, wind power is among the most efficient sources of energy, which has been significantly growing over the past decades. In order to establish a high efficiency wind farm, multiple parameters are to consider belonging to the wind resource assessment, wind turbine design and wind farm layout design optimization (Barthelmie and Jensen, 2010; Jamieson, 2018). 
Wind resource assessment consists of the process of collecting and analysing the wind resource data, studying the wind speed characteristics and determining the viability of the wind resource in the studied region. After selecting a suitable site, it is essential designing an efficient wind turbine, which matches the characteristics of that site. This consists of configuring the wind turbine parameters, such as the power coefficient, blade parameters, tip speed ratio, drag to lift ratio, air foil section and other related parameters (Saeidi et al., 2013). Finally, the wind farm design process consists of the optimum positioning and arrangement of the wind turbines, the techno-economic and environmental assessment of the wind farm (Chen et al., 2013). Hence, the arrangement of wind turbines in the wind farm is affected by different factors which should be taken into consideration. Examples of these factors are: wind direction, wind energy distribution, the availability of the land and the possibility of construction.

The wake effect has a substantial impact on the energy production of a wind turbine. This effect is typically generated during harnessing wind power by wind turbines blades, which can then spread and lead to turbulence and wind speed variations, resulting in reduction of the energy production of the other neighbouring wind turbines in the wind farm. In addition, while the wind farm efficiency is greatly contingent upon the distribution of the wind speeds and wind direction, it has also been proven that the impact of turbine positioning on the wake loss, and wind turbine efficiency are considerable.

Ozturk and Norman (2004) employed a heuristic greedy approach to optimize a wind farm with the purpose of maximizing its profitability. In latest studies, the genetic algorithm (GA) consisting of its evolutionary and multi-population types has been used to address the wind farm optimization problem (Zhao et al., 2009; González et al., 2018; Grady et al., 2005; Park \& Law, 2015). Moseti et al. (1994) proposed a new optimization model for a wind farm by subdividing a square wind farm into a $10 \times 10$ grid layout. Park and Law (2015) described an efficient method for optimizing the placement of wind turbines to maximize the expected wind farm power. Kallioras et al. (2015) presented an optimum layout design of an onshore wind farm by taking into account the stochastic loading. Feng and Shen (2017) carried out the design and optimization of offshore wind farms by considering multiple types of wind turbines. Gao et al. (2014) presented an analysis of wind power potential and wind farm optimization with the aim of achieving a minimum cost of energy with a maximum power generation by utilizing the GA approach. Kuo et al. (2016) investigated the wind farm layout optimization on complex terrains through combining a CFD wake model with the mixed integer programming. Knudsen et al. (2015) conducted a survey on the wind farm control and fatigue optimization. Two primary purposes of this research were to maximize the overall wind farm production and to minimize the fatigue loading for wind turbines. Chamorron et al. (2014) argued that the implementation of the variable-sized wind turbines would lead to enhancing the optimization of the wind farm. Shakoor et al. (2016) proposed the wind farm layout optimization by taking into account the wake effect and considering the Jensen's model. Machefaux et al. (2015) studied the engineering models for merging wakes during the wind farm optimization process. Parada et al. (2017) performed the wind farm layout optimization using a Gaussian-based wake model with the aim of minimizing the annual cost of energy. Wang and Zhang (2018) proposed a new encoding mechanism for the locations of wind turbines according to the characteristics of the layout of the wind farm. Their presented method was able to obtain the optimal overall performance of the wind farm.

By categorizing the optimization goals and the applied methods, a summary of a set of recent studies is in Table 1.

Among all the objective functions, the energy production is frequently used during the design process. Cost and wake loss have also been widely used in the recent studies. A parameter affecting such objective functions is the wind tower layout, which is frequently analyzed during the analysis. Other contributory factors, which are less considered, include the number of wind turbines, some aerodynamic parameters such as the angle of attack together with other technical parameters including the power coefficient and the noise propagation.

Looking at the design methodologies, metaheuristics and mathematical modelling techniques are widely utilized during the analysis process. Other less commonly used methods include sequential convex and mixed integer programming, Monte Carlo analysis and Artificial Neural Networks (ANNs). Finally, in most cases, the wake effect is considered during the design process. 
Table 1. Analysis on selected flood damage assessment studies

\begin{tabular}{|c|c|c|c|c|c|c|c|c|c|c|c|c|c|c|}
\hline \multirow[b]{2}{*}{$\stackrel{\frac{1}{\bar{\varpi}}}{\rightleftharpoons}$} & \multirow[b]{2}{*}{$\begin{array}{l}\text { ज़ } \\
\frac{1}{0} \\
\frac{1}{3} \\
\frac{3}{4}\end{array}$} & \multicolumn{6}{|c|}{ Optimization goals } & \multicolumn{5}{|c|}{ Methods } & \multicolumn{2}{|c|}{ Wake effect } \\
\hline & & 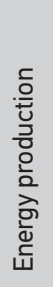 & जू & 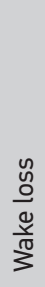 & 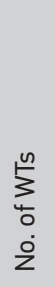 & 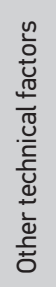 & 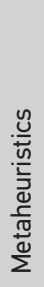 & 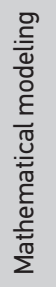 & 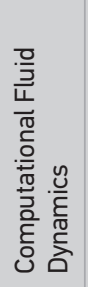 & 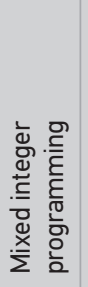 & $\begin{array}{l}\frac{0}{1} \\
\text { ग } \\
0 \\
\stackrel{0}{0} \\
\frac{0}{\Sigma}\end{array}$ & 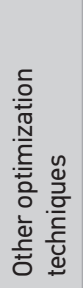 & $\stackrel{y}{\rightleftharpoons}$ & 운 \\
\hline 2004 & Ozturk and Norman & & & & & & & & & & & & & \\
\hline 2005 & Grady et al. & $x$ & $x$ & & & & $x$ & & & & & & & $x$ \\
\hline 2009 & Zhao et al. & $x$ & $x$ & & & $x$ & $x$ & & & & & & & $x$ \\
\hline 2012 & Ekonomou et al. & $x$ & & & $x$ & & & & & & & & & $x$ \\
\hline 2012 & Kwong et al. & $x$ & & & & $\mathrm{x}$ & $x$ & & & & & & $x$ & \\
\hline 2013 & Ghofrani et al. & & $x$ & & & & $x$ & $x$ & & & & & & $x$ \\
\hline 2013 & Siano \& Mokryani & & $x$ & & & & $x$ & & & & & & & $x$ \\
\hline 2014 & Chen \& MacDonalds & & $x$ & & & & $x$ & & & & & & $x$ & \\
\hline 2014 & Gaumond et al. & $x$ & & & $x$ & & & $x$ & & & & & $x$ & \\
\hline 2014 & Turner et al. & $x$ & & $x$ & & & & $x$ & & $\mathrm{x}$ & & & $x$ & \\
\hline 2014 & Gao et al. & $x$ & $x$ & & & & $x$ & & & & & & $x$ & \\
\hline 2014 & Zhang et al. & $x$ & $x$ & $x$ & & $\mathrm{x}$ & & & & $\mathrm{x}$ & & & $x$ & \\
\hline 2015 & Park and Law & $x$ & & & & & & $x$ & & & & $x$ & $x$ & \\
\hline 2015 & Hou et al. & $x$ & $x$ & $x$ & & $\mathrm{x}$ & $x$ & $x$ & & & & & $x$ & \\
\hline 2015 & Feng \& Shen & & & $x$ & & & $x$ & & & & & $\mathrm{x}$ & $x$ & \\
\hline 2015 & Knudsen et al. & $x$ & & & & $x$ & & $x$ & & & & $x$ & $x$ & \\
\hline 2015 & Kallioras et al. & $x$ & $x$ & & & & $x$ & & & & & & & $x$ \\
\hline 2016 & Bartl \& Sætran & & & $x$ & & $x$ & & & $x$ & & & & $x$ & \\
\hline 2016 & Guirguis et al. & $x$ & $x$ & & & $x$ & $x$ & & & & $x$ & & $x$ & \\
\hline 2016 & Kuo et al. & $x$ & $x$ & $x$ & & & & & $x$ & $x$ & & & $x$ & \\
\hline 2017 & Yin et al. & $x$ & $x$ & $x$ & & & $x$ & & & & $x$ & & $x$ & \\
\hline 2017 & Parada et al. & $x$ & $x$ & & & & $x$ & $x$ & & & & & $x$ & \\
\hline 2017 & Gebraad \& Thomas & $x$ & & $x$ & & & & $x$ & & & & & $x$ & \\
\hline 2018 & Wang \& Zhang & $x$ & & & & & & $x$ & & & & & $x$ & \\
\hline 2018 & Kanev et al. & $x$ & & $x$ & & $x$ & & $x$ & & & & & $x$ & \\
\hline 2018 & González et al. & $x$ & $x$ & & & & $x$ & & & & & & $x$ & \\
\hline
\end{tabular}


This research is written and developed with a motivation to investigate the performance of a large-scale wind farm by considering different arrangements and positions of wind turbines in the wind farm. Through presenting a novel multi-scenario analysis, the objective of the study was to analyze and examine the optimum techno-economic viability under effect of the following decision variables: number of wind turbines, the wind turbines self-distance, and their distance in relation with the grid line. The energy production and cost were assumed to be the primary objective functions. A comparative analysis was also conducted to explore the performance assessment of each wind farm according to the positions of wind turbines in the wind farm.

The paper begins from this background presenting a multi-scenario cost-based real application, geo-located in Iran, investigating the effects of different layouts of the wind turbines on the economic performances and the cost of energy. According to this goal, the remainder of the paper is as follows. Section 2 revises the design methodology of the research. Section 3 introduces the application and the case scenario, while Section 4 shows the results of the analysis. In the last Section 4, conclusions and recommendations for future research are presented.

\section{Methods}

The harnessed power of the wind, by wind turbines in a wind farm, can be calculated according to (1) (Yin et al., 2017):

$$
P(u)=\frac{1}{2} c_{p} \eta \rho A u^{3}
$$

Where $P$ is the generated electrical power, $\eta$ is the overall efficiency of the wind turbine, $\rho$ is the air density, $A$ is the swept area of the wind turbine, $u$ is the free stream wind velocity, $c_{p}$ is the power coefficient of the wind turbine, defined in (2).

$$
C_{p}=\frac{P_{A}}{\left(\frac{1}{2}\right) \rho A u_{0}^{3}}
$$

Where $P_{A}$ represents the aerodynamic rated power output of the wind turbine at the nominal wind speed $u_{0}$ (Gebraad et al., 2017).
In the first stages of analyzing the viability of the wind resource and energy production, it is a prerequisite to determine the distribution of the studied wind resource. Recently, it has become evident that the Weibull distribution is the most efficient distribution function, which has a great fitting with the actual wind data. The probability density function (PDF) of the Weibull distribution is in (3) (Barthelmie \& Jensen, 2010).

$$
f(\mathrm{u})=\frac{k}{c}\left(\frac{u}{c}\right)^{k-1} e^{-\left(\frac{u}{c}\right)^{k}}
$$

Where $k$ and $c$ are the so-called shape and scale factors, respectively. The cumulative density function (CDF) is in (4).

$$
F(\mathrm{u})=1-e^{-\left(\frac{u}{c}\right)^{k}}
$$

Using (4), it is possible to estimate the percentages and frequencies of wind speed in the studied site. Hence, it is possible to determine the probability of a specific wind speed value in the wind farm, which makes easier for the wind farm designers to take accurate decisions during the design of wind turbines and the wind farm for the studied site.

Furthermore, if the height of the wind turbines in the wind farm is not the same as the height for the meteorological site, it is essential to extrapolate the wind data to the wind turbine's hub height. Therefore, equation (5) is considered to estimate the wind speed from a reference height.

$$
u(z)=\frac{u^{*}}{h} \ln \left(\frac{z}{z_{0}}\right) \text { if } z>z_{0}, u(z)=0 \text { if } z \leq z_{0}
$$

Where $u(z)$ is the wind speed at height $z, U^{*}$ is the friction velocity, $h$ is the von Karman's constant and $z_{0}$ is the surface roughness, which is estimated to be $0.00574 \mathrm{~m}$ (Nedaei et al., 2014). The detailed procedure for calculating $z_{0}$ is performed on the basis of the mentioned reference (Nedaei et al., 2014).

Equation (5) is also used to study the variations in height. In this regard, for the purpose of vertical extrapolation of wind speed, wind speed at $40 \mathrm{~m}$ height was extrapolated, and the new wind speed was estimated at 90 $\mathrm{m}$ height. This height $(90 \mathrm{~m})$ is applied as the amount of height according to the wind turbine's hub height 
configuration for installation of the Vestas V100 wind turbine in the wind farm. The $40 \mathrm{~m}$ height is considered the basis for the meteorological mast (i.e., the 40 $\mathrm{m}$ height is the height for recording meteorological wind speed data).

In this study, the effect of wake on the wind turbines is considered. The well-known Jensen's model allows estimating the wind speed under the effect of the surrounding wind turbines (Saeidi et al., 2013). This model has been developed according to a mass-conserving engineering model for predicting the hub height wind speed downstream of a turbine, $u_{1}$, when subjected to a hub height inflow wind speed $u_{2}$ (Wang et al., 2018).

$$
u_{2}=u_{1}\left[1-\left(1-\sqrt{1-c_{t}}\right)\left(\frac{r}{r+2 l x}\right)^{2}\right]
$$

Where $r$ is the rotor radius, $l$ is the wake constant, $x$ is the distance from the considered wind turbine in the wake effect and $c_{t}$ is the thrust coefficient. $c_{t}$ acts as a function of an axial induction factor indicating how much the energy extracted from the turbine affects the fluid flow. The thrust coefficient can be calculated according to (7) (Hwang et al., 2015).

$$
C_{t}=\frac{T}{\left(\frac{1}{2}\right) \rho A u^{2}}
$$

Where $T$ is the thrust force, $\rho$ is the air density, $u$ is the wind speed and $A$ is the rotor cross section. Using (1)(7), the cumulative energy production follows in (8):

$$
U=\int_{u_{\min }}^{u_{\max }} P(u) f(u) d u
$$

Where $u_{\min }$ is the cut-in speed and $u_{\max }$ is the cut-out speed of the wind turbine (Hwang et al., 2015).

The long-term sustainability of a wind farm is the economic target behind the design of the wind farm layout, while the LCOE is the indicator for assessing the overall viability of energy projects. The LCOE determines how much investments should be considered per unit of electricity in order to recover the lifetime costs of the system. The LCOE is defined in (9) (Karlsen et al., 2009; USDE, 2015).

$$
L C O E=\sum_{i=0}^{n} \frac{F_{1}}{(1+r)^{i}} / \sum_{i=1}^{n} \frac{A E P_{i}}{(1+r)^{i}}
$$

Where $F_{1}$ indicates the annual cost in year $i, n$ is the project lifetime, $A E P_{1}$ is the annual energy production in year $i$, and $r$ is the weighted average cost of capital to discount the cash flows. The numerator of (9) is the net present value (NPV) of the wind farm project.

$$
N P V=\sum_{i=0}^{N} \frac{F_{i}}{(1+r)^{i}}
$$

It is noted that for the purpose of economic analysis using the NPV and the LCOE, the investment, operation and maintenance costs, discount rate (weighted average cost of capital to discount the cash flows), and the annual energy production were taken into consideration. These parameters were used according to the definition of the governing equations developed for the NPV and the LCOE as further described in Equations (9) and (10). The data regarding the above-mentioned parameters were also reported in Table 3. In the case of annual energy production, the energy production values are analyzed according to obtained results in Tables 5 and 6 .

\section{Multi-scenario application}

In order to verify the presented approach, a case study of the meteorological site of Kish Island in Iran is selected. Fig. 1 shows the wind direction of the studied site at $90 \mathrm{~m}$ height.

As can be indicated in Fig. 1, the predominant wind direction for the studied site at the hub height wind speed is coming from north-west within the direction sectors of $300^{\circ}$ and $330^{\circ}$ with percentages up to approximately $13 \%$. There was also minor wind potential observed in other direction sectors of the polar diagram depicted in Fig. 1.

Following the methodology outlined in Section 2, a multi-scenario assessment is proposed screening different layouts of the wind farm. In the energy site, the wind turbines to be installed are assumed to be the same, with a $2 \mathrm{MW}$ capacity each. The proposed scenarios are based on the number of the wind turbines, their reciprocal 
Fig. 1. Wind direction diagram at $90 \mathrm{~m}$ height in the studied site

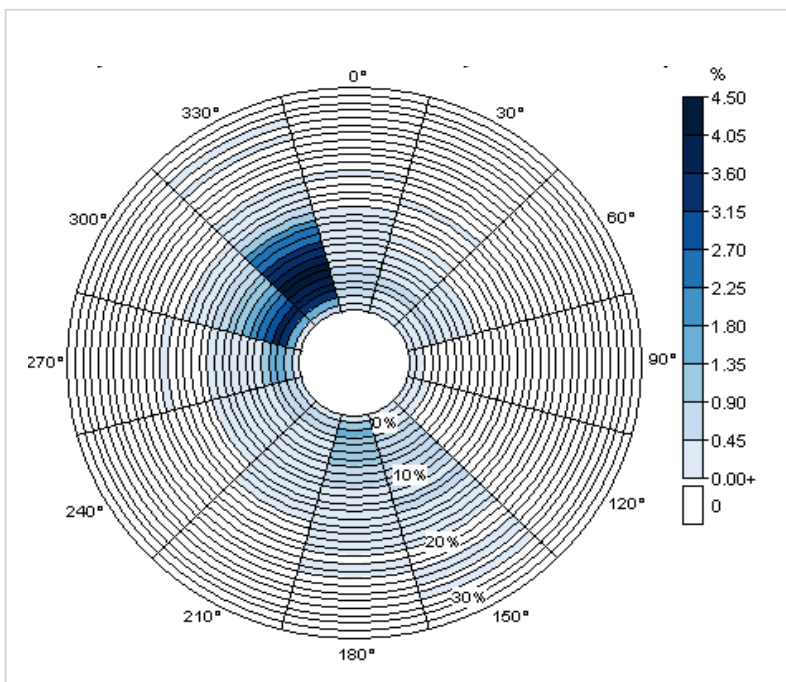

position and their position respect to the main wind direction. The available area of the wind farm, which is on a rectangular form, equals to $450 \times 450 \mathrm{~m}^{2}$. A grid system together with a power controller is situated outside this area. Fig. 2 presents a schematic of the proposed wind farm and the grid electricity system further presenting the first tested layout made of four wind turbines, i.e., Structure 1 in the following.

As demonstrated in Figs. 2-7, 5 structures were designed with a wide range of positioning scenarios. The objective was to evaluate the efficiency of the wind farm according to the following decision variables: the number of wind turbines, the wind turbines self-distance, and their distance in relation with the grid line. With a wind farm capacity of 8MW, Structures 1 and 2 were designed. In Structure 1, the turbines are randomly distributed in different regions of the wind farm. Structure 2 indicates that the position of the wind turbines has been situated in close distance to the grid line, nevertheless far from the primary wind source coming to the wind farm. Through considering a larger-scale wind farm, Structures 3-5 were designed. In each structure, in order to evaluate the performance of the wind farm, the wind turbines were situated in different regions of the wind farm. Such an arrangement was performed based on both random positioning and positioning according to turbines distance in order to measure the effect of turbines self-distance and turbines distance in relation with the primary grid line on energy production and cost of electricity.

Wind turbine data. In this study, a Vestas V100 wind turbine is selected. The turbine data are in Table 2. Furthermore, in this study, no yaw control is applied during the analysis and it is assumed that the blades are orthogonal to the wind direction.

Fig. 3 depicts the power curve diagram of the considered turbine, while costs and economic variables
Fig. 2. Schematic of the proposed wind farm, grid line and Structure 1.

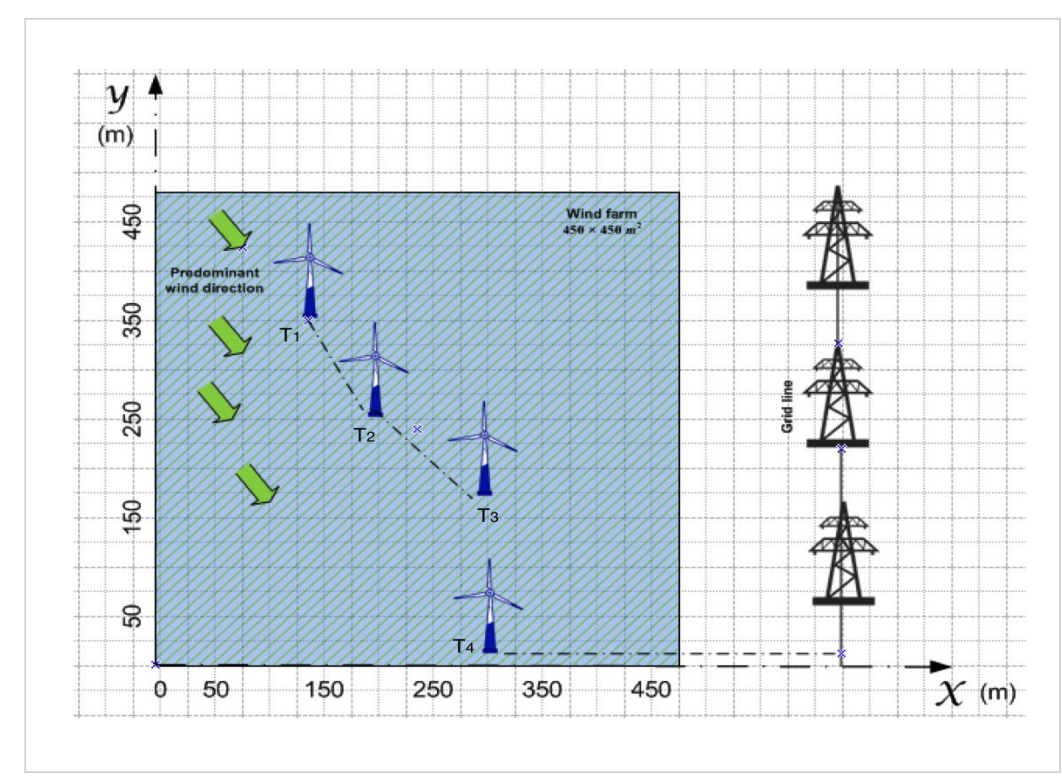

Table 2. Wind turbine key technical data

\begin{tabular}{l|c}
\multicolumn{1}{c|}{ Turbine model } & Vestas V100 \\
\hline Capacity (MW) & 2 \\
\hline $\begin{array}{l}\text { Wind turbine hub } \\
\text { height (m) }\end{array}$ & 90 \\
\hline $\begin{array}{l}\text { Meteorological } \\
\text { mast height (m) }\end{array}$ & 40 \\
\hline $\begin{array}{l}\text { Rotor radius (m) } \\
\text { Swept area (m2) }\end{array}$ & 55 \\
\hline $\begin{array}{l}\text { Design thrust } \\
\text { coefficient }\end{array}$ & 9,503 \\
\hline $\begin{array}{l}\text { Overall loss factor } \\
\text { for single turbine } \\
\text { (\%) }\end{array}$ & 0.8 \\
\hline
\end{tabular}


Fig. 3. Wind turbine power curves..

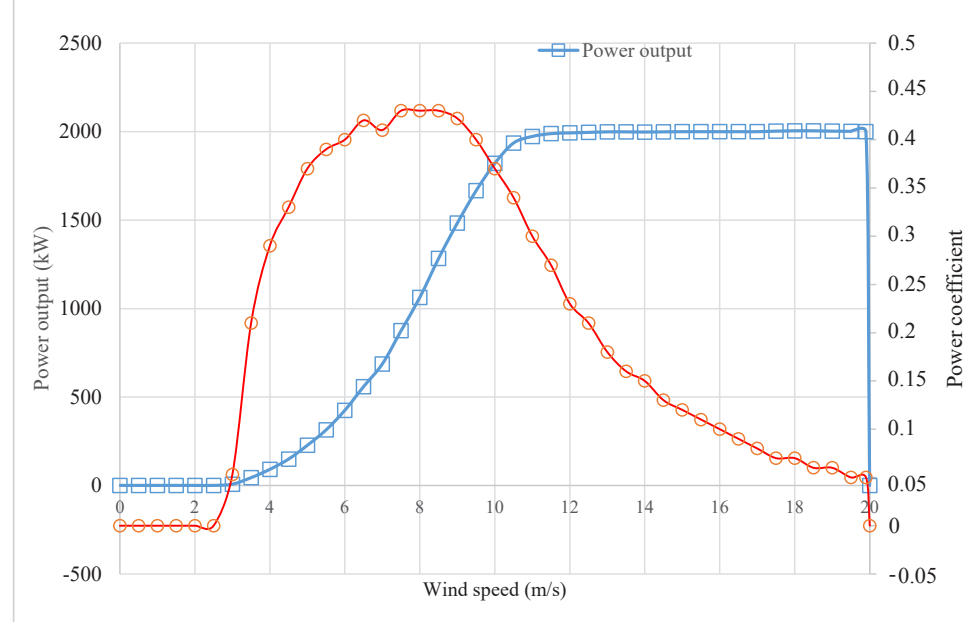

Fig. 4. Schematic of the proposed wind farm, Structure 2.

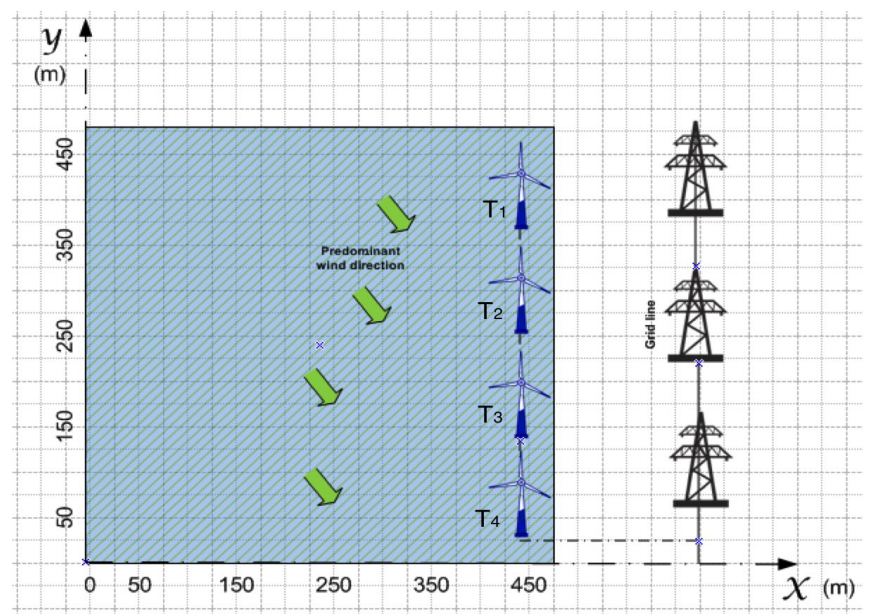

Fig. 5. Schematic of the proposed wind farm, Structure 3.

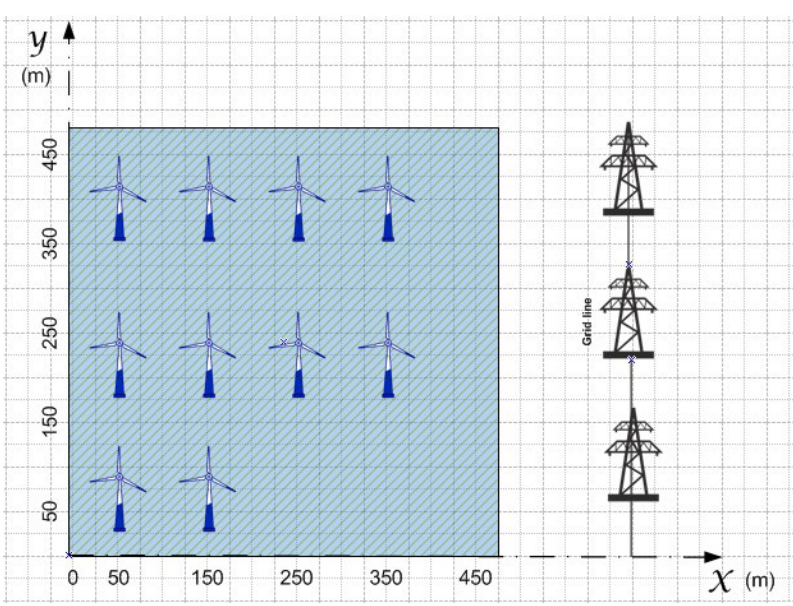

related to each turbine and the entire wind farm are summarized in Table 3.

Table 3. Costs and economic parameters.

\begin{tabular}{l|c}
\hline Parameter & Value \\
\hline Investment cost $(€)$ & $1,530,466$ \\
\hline O\&M cost $(€)$ & 80,000 \\
\hline Inflation rate (\%) & 12 \\
\hline Discount rate (\%) & 10 \\
\hline Plant lifetime (years) & 20 \\
\hline
\end{tabular}

Two macro-scenarios of the wind farm are considered, varying the installed power.

First macro-scenario: $8 \mathrm{MW}$ wind farm. This macro-scenario consists of three scenarios for positioning of the wind turbines:

1 The arrangement of the wind turbines in the wind farm was performed according to Fig. 2 and no assumptions for the wake effect were considered.

2 The arrangement of the wind turbines was considered according to Fig. 2. However, unlike the previous scheme, the wake effect is taken into account during the analysis.

3 The structure is according to Fig. 4 (Structure 2). In this situation, it is noted that the distance to the grid is reduced and the effect of wake is less significant due to the fact that wind turbines are situated on a vertical line on the map.

\section{Second macro-scenario: 20MW wind farm.}

This macro-scenario aims at increasing the installed power and, consequently, the number of wind turbines. Due to the available area, interferences among blades increase. Figs. 5-7 depict the three structures to analyze corresponding to a same number of scenarios. Details are as follows.

1 Structure 3 of Fig. 5. Wind turbines are placed in the wind farm with a distance of $100 \mathrm{~m}$ in relation with each other. The wind turbines from the right hand side of the wind farm have a distance of $175 \mathrm{~m}$ until the primary grid line. Eight sets of wind turbines are equally distributed in the first and 
second rows, whilst two sets of turbines are located in the third row. The distance of each row in relation with another row is $325 \mathrm{~m}$.

2 Structure 4 of Fig. 6. The wind turbines are located in the path of the predominant wind direction and they are mostly in the central part of the wind farm and, therefore, closer to each other. The purpose of this structure has been to reduce the wind farm's occupied space as much as possible.

3 Structure 5 of Fig. 7. Each of the wind turbines is located close to the border/axis of the wind farm and, therefore, unlike the second structure, they are no longer distributed in the central parts of the wind farm. Distance of each row in relation with another one is of about $175 \mathrm{~m}$. The turbines in the first and the third rows have a distance of $125 \mathrm{~m}$ in relation with each other, whereas the turbines in the second row have a distance of $400 \mathrm{~m}$.

Table 4 demonstrates the number of wind turbines for each scenario and structure.

Table 4. The number of wind turbines according to each configuration

\begin{tabular}{|c|c|c|c|}
\hline 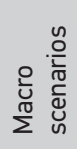 & 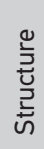 & 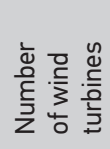 & 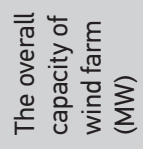 \\
\hline \multirow{2}{*}{1} & 1 & 4 & 8 \\
\hline & 2 & 4 & 8 \\
\hline \multirow{3}{*}{2} & 3 & 10 & 20 \\
\hline & 4 & 10 & 20 \\
\hline & 5 & 10 & 20 \\
\hline
\end{tabular}

\section{Results and Discussion}

This section elaborates the obtained results of the analysis. As a matter of fact, the distribution analysis of the wind resource is a primary aspect of the evaluation process for any wind energy project, which aims to consider the installation and development of the wind turbines in any considered regions. The distribution analysis was performed on the basis of the Weibull
Fig. 6. Schematic of the proposed wind farm, Structure 4.

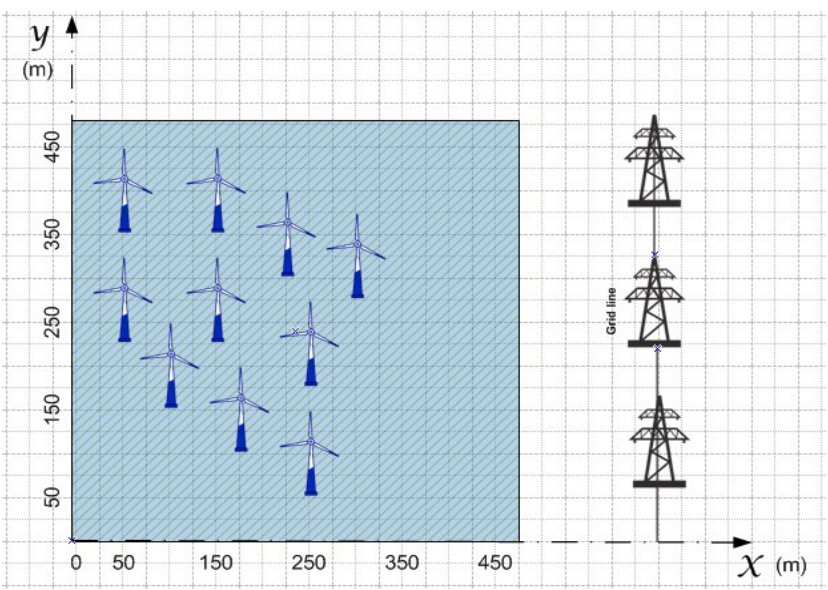

Fig. 7. Schematic of the proposed wind farm, Structure 5.

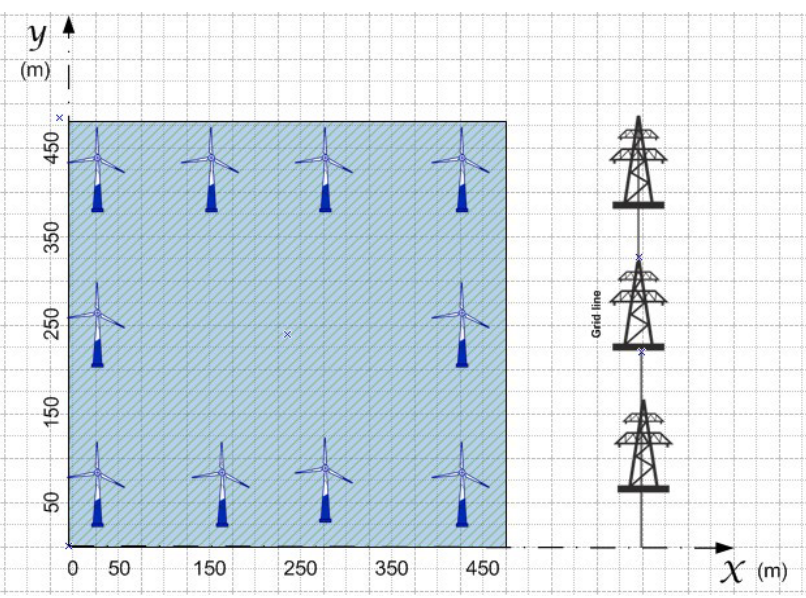

Fig. 8. Frequency and distribution analysis of the wind speed in the studied site.
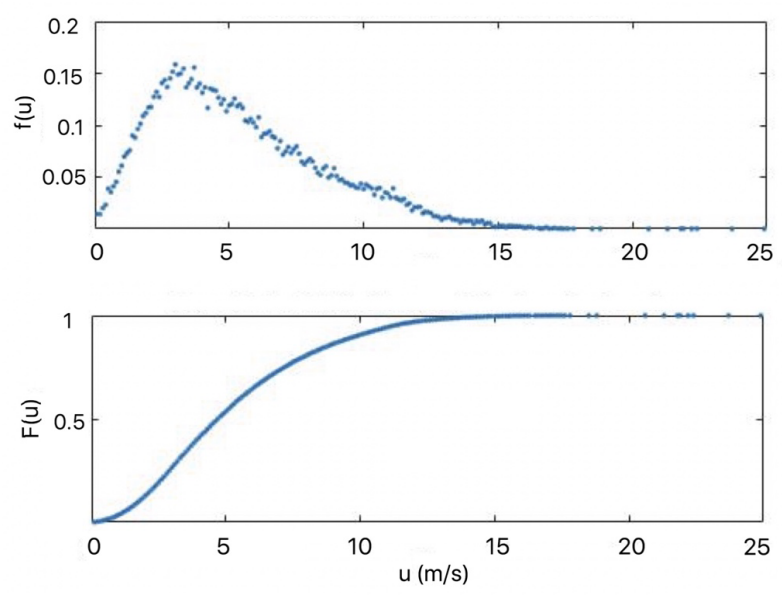
distribution, which is shown in Fig. 8 demonstrating the frequency analysis of the wind resource. As it is clear, the fitted distribution function has a peak value at approximately $3.5 \mathrm{~m} / \mathrm{s}$. Furthermore, the cumulative distribution analysis in Fig. 8 shows the frequencies of wind occurring at different wind speed levels.

The calculation of the energy production and cost of wind energy production are the next step of this study. Tables 5 and 6 depict the primary techno-economic parameters including the energy production, LCOE and NPV for each proposed scenario.

Table 5. Multi-scenario analysis results for the first macro-scenario

\begin{tabular}{l|l|l|c|l}
\hline Scenario & Structure & $\begin{array}{c}\text { Produced } \\
\text { energy }[\mathrm{MWh}]\end{array}$ & $\begin{array}{c}\text { NPV } \\
{[€]}\end{array}$ & $\begin{array}{c}\text { LCOE } \\
{[\text { cent/kWh] }}\end{array}$ \\
\hline 1 & 1 & 23,896 & $22,660,548$ & 6.862 \\
\hline 2 & 1 & 16,224 & $10,900,960$ & 10.108 \\
\hline 3 & 2 & 22,776 & $21,026,252$ & 7.200 \\
\hline
\end{tabular}

Table 6. Multi-scenario analysis results for the second macro-scenario

\begin{tabular}{l|l|l|l|l}
\hline Scenario & Structure & $\begin{array}{c}\text { Produced } \\
\text { energy [MWh] }\end{array}$ & $\begin{array}{c}\text { NPV } \\
{[€]}\end{array}$ & $\begin{array}{c}\text { LCOE } \\
{[\text { cent/kWh] }}\end{array}$ \\
\hline 1 & 3 & 54,700 & $44,302,490$ & 8.72 \\
\hline 2 & 4 & 30,220 & $7,761,860$ & 14.98 \\
\hline 3 & 5 & 55,349 & $46,262,430$ & 8.43 \\
\hline
\end{tabular}

The numerical analysis for the energy production was conducted according to Equation 8 described in the methodology section. On this basis, the wind turbine energy analysis module of the Windographer software was adopted to calculate and analyze the numerical results (Windographer, 2019).

By comparing the estimated values for the cost indicators, it can be inferred that the NPV is in accordance with the LCOE. Additionally, in the first macro-scenario, by taking into account the effect of wake, the maximum profitability is for the second wind farm structure, which is, therefore, the most energy-efficient. In the second macro-scenario, the optimum values for the techno-economic parameters is in the fifth proposed structure. By using this structure, the wind farm LCOE is estimated to be $8.43 € / \mathrm{kWh}$. However, among all the studied scenarios, the maximum LCOE is calculated to be $14.98 € / \mathrm{kWh}$, which shows less efficiency of the wind farm for the wind energy production using the fourth structure. Furthermore, the comparison of the two proposed macro-scenarios shows that establishing a lower size wind farm in the studied site is more economical rather than a larger-scale wind farm. The LCOE varies from 6.862 to $10.108 € / \mathrm{kWh}$ considering the first macro-scenario, whereas for the second-macro scenario, it ranges from 8.43 to $14.98 € / \mathrm{kWh}$. It is also noted that the NPV for the second-macro scenario using the fourth structure is lower than the NPV values estimated in the first macro-scenario, which shows the lower efficiency of the wind farm due to the wake effect between the wind turbines, when this structure is implemented.

Overall, it can be concluded that the wind farm efficiency in terms of the power production and the cost of wind energy production significantly depends on positioning of the wind turbines in a wind farm. Therefore, it is crucial arranging the turbines using the most suitable approach in order to reach the maximum energy efficiency for the wind farm. Hence, further research can be performed to investigate positioning of the wind turbines by comparing the current results with other case studies and wind farm structures. A greater number of decision variables should also be considered in order evaluate the wind farm performance under further operating conditions.

\section{Conclusions}

This paper studies the techno-economic design of wind farms presenting a multi-scenario cost-based application. In the first step, a review of the latest advancements in the field of wind farm design and optimization along with wind resource assessment is carried out. It has become evident that little attention has been given for the design of the wind farm by taking into account the number and arrangement of the wind turbines in the wind farm. This issue is particularly important in order to minimize the LCOE.

The proposed methodology of the research is applied to a wind farm area of $450 \times 450 \mathrm{~m}$. A case study in the Kish Island in Iran is considered and the wind resource data are extracted and analyzed from a meteorological mast in the studied area. The distribution analysis is performed on the basis of the Weibull distribution 
function. The wake effect is then calculated using the Jensen's model. Different structures for positioning of the wind turbines are considered together with two macro-scenarios, i.e., low and high installed power.

The results demonstrate the effect of the positioning of the wind turbines, which lead to different values of the LCOE, the NPV, and the energy production for the proposed wind farm and macro-scenarios. The NPV values for the first macro-scenario range from minimum of $10,900,960 €$ up to maximum of $22,660,548$ $€$ using the first structure. This structure of the wind farm also leads to the least LCOE and maximum energy production making it the most suitable scheme for establishing the wind farm. In the second macro-scenario, the estimated NPV values are much higher

\section{References}

Barthelmie R.J. and Jensen L.E. (2010) Evaluation of wind farm efficiency and wind turbine wakes at the Nysted offshore wind farm. Wind Energy 13(6): 573-586. https://doi. org/10.1002/we.408

Bartl J., and Sætran L. (2016). Experimental testing of axial induction based control strategies for wake control and wind farm optimization. In: Journal of Physics: Conference Series, 753(3), pp. 032035, IOP Publishing. https://doi. org/10.1088/1742-6596/753/3/032035

Chen Y., Li H., Jin K. and Song, Q. (2013). Wind farm layout optimization using genetic algorithm with different hub height wind turbines. Energy Conversion and Management 70: 56-65. https://doi.org/10.1016/j.enconman.2013.02.007

Chen L., and MacDonald E. (2014). A system-level cost-of-energy wind farm layout optimization with landowner modeling. Energy Conversion and Management 77: 484-494. https://doi. org/10.1016/j.enconman.2013.10.003

Chamorro L.P., Tobin, N., Arndt R.E. A., and Sotiropoulos, F. (2014). Variable-sized wind turbines are a possibility for wind farm optimization. Wind Energy 17(10): 1483-1494. https:// doi.org/10.1002/we.1646

Clean Energy Project Analysis, RETScreen Engineering \& Cases Textbook, Clean Energy Decision Support Center, Third Edition, September 2005.

Ekonomou L., Lazarou S., Chatzarakis G.E. and Vita, V. (2012) Estimation of wind turbines optimal number and produced power in a wind farm using an artificial neural network model. Simulation Modelling Practice and Theory 21(1): 21-25. https://doi.org/10.1016/j.simpat.2011.09.009 owing to the bigger capacity of the wind farm. They range from a minimum of $7,761,860 €$ in the fourth structure up to a maximum of $46,262,430 €$ using the fifth structure. Hence, considering the arrangement of the wind turbines in the wind farm, the most viable structure is determined to be the first structure in the first macro-scenario and the fifth structure in the second macro-scenario. Overall, it is shown that the wind farm techno-economic viability heavily depends on arrangement and position of the turbines in the wind farm. We recommend further research for investigating a comparison of the results with other cost models and wind farm structures and to assess the wind farm viability under a wider range of decision variables.

Feng J., and Shen W.Z. (2015) Solving the wind farm layout optimization problem using random search algorithm. Renewable Energy 78: 182-192. https://doi.org/10.1016/j. renene.2015.01.005

Feng J., and Shen W.Z. (2017). Design optimization of offshore wind farms with multiple types of wind turbines. Applied Energy 205: 1283-1297. https://doi.org/10.1016/j.apenergy.2017.08.107

FT. Exploring Science and Technology, Watson, D.E., "wind turbine power coefficient (Cp), http://www.ftexploring.com/ wind-energy/wind-power-coefficient.htm [Accessed January, 2019].

Gao X., Yang H., and Lu L. (2014). Study on offshore wind power potential and wind farm optimization in Hong Kong. Applied Energy 130: 519-531. https://doi.org/10.1016/j.apenergy.2014.02.070

Gebraad P., Thomas J.J., Ning, A., Fleming, P., and Dykes, K. (2017) Maximization of the annual energy production of wind power plants by optimization of layout and yaw-based wake control. Wind Energy 20(1): 97-107. https://doi.org/10.1002/ we. 1993

González J.S., Payán, M.B. and Santos J.M.R. (2018). Optimal design of neighbouring offshore wind farms: A co-evolutionary approach. Applied Energy 209: 140-152. https://doi. org/10.1016/j.apenergy.2017.10.120

Gaumond M., Réthoré P.E., Ott, S., Pena, A., Bechmann, A. and Hansen, K.S. (2014). Evaluation of the wind direction uncertainty and its impact on wake modeling at the Horns Rev offshore wind farm. Wind Energy 17(8): 1169-11 https://doi. org/10.1002/we.1625 
Grady S.A., Hussaini, M.Y. and Abdullah, M.M. (2005). Placement of wind turbines using genetic algorithms. Renewable Energy 30(2): 259-270. https://doi.org/10.1016/j. renene.2004.05.007

Ghofrani M., Arabali A., Etezadi-Amoli M., and Fadali M. S. (2013) A framework for optimal placement of energy storage units within a power system with high wind penetration. IEEE Transactions on Sustainable Energy 4(2): 434-442. https://doi. org/10.1109/TSTE.2012.2227343

Guirguis D. Romero, D.A. and Amon C.H. (2016) Toward efficient optimization of wind farm layouts: Utilizing exact gradient information. Applied Energy 179: 110-123. https://doi. org/10.1016/j.apenergy.2016.06.101

Hwang C., Jeon J.H., Kim G.H., Kim E., Park, M., and Yu, I.K. (2015) Modelling and simulation of the wake effect in a wind farm. Journal of International Council on Electrical Engineering 5(1): 74-77. https://doi.org/10.1080/22348972.2015.1109793

Hou P., Hu W., Soltani M., and Chen, Z. (2015) Optimized placement of wind turbines in large-scale offshore wind farm using particle swarm optimization algorithm. IEEE Transactions on Sustainable Energy 6(4): 1272-1282. https://doi.org/10.1109/ TSTE.2015.2429912

Jamieson P. (2018). Innovation in wind turbine design. John Wiley \& Sons. https://doi.org/10.1002/9781119137924

Karlsen J.A. (2009) Performance calculations for a model turbine (Master's thesis, Institutt for energi-og prosessteknikk). NTNU. Trondheim, Norway.

Kanev S. K., Savenije, F.J., and Engels, W.P. (2018). Active wake control: An approach to optimize the lifetime operation of wind farms. Wind Energy 21(7): 488-501. https://doi. org/10.1002/we.2173

Kallioras N.A., Lagaros N.D., Karlaftis M.G., and Pachy P. (2015). Optimum layout design of onshore wind farms considering stochastic loading. Advances in Engineering Software 88: 8-20. https://doi.org/10.1016/j.advengsoft.2015.05.002

Kwong W.Y., Zhang P.Y., Romero D., Moran J., Morgenroth M., and Amon, C. (2012) Wind farm layout optimization considering energy generation and noise propagation. In: ASME 2012 International Design Engineering Technical Conferences and Computers and Information in Engineering Conference, pp. 323-332, American Society of Mechanical Engineers. https:// doi.org/10.1115/DETC2012-71478

Kuo J.Y., Romero D.A., Beck J.C. Amon C.H. (2016). Wind farm layout optimization on complex terrains-Integrating a CFD wake model with mixed-integer programming. Applied Energy 178: 404-414. https://doi.org/10.1016/j.apenergy.2016.06.085

Knudsen, T., Bak, T., and Svenstrup, M. (2015). Survey of wind farm control-power and fatigue optimization. Wind Energy
18(8): 1333-1351. https://doi.org/10.1002/we.1760

Machefaux E., Larsen, G.C., and Leon, J. M. (2015) Engineering models for merging wakes in wind farm optimization applications. In: Journal of Physics: Conference Series, 625(1), p. 012037. IOP Publishing. https://doi.org/10.1088/17426596/625/1/012037

Mosetti G., Poloni, C. and Diviacco, B. (1994) Optimization of wind turbine positioning in large windfarms by means of a genetic algorithm. Journal of Wind Engineering and Industrial Aerodynamics 51(1): 105-116. https://doi.org/10.1016/01676105(94)90080-9

Nedaei M. (2014) Wind resource assessment in Hormozgan province in Iran. International Journal of Sustainable Energy 33(3): 650-694. https://doi.org/10.1080/14786451.2013.7843 19

Ozturk U.A. and Norman, B.A. (2004). Heuristic methods for wind energy conversion system positioning, Electric Power Systems Research 70 (3): 179-185. https://doi.org/10.1016/j. epsr.2003.12.006

Parada L., Herrera C., Flores P., and Parada, V. (2017) Wind farm layout optimization using a Gaussian-based wake model. Renewable Energy 107: 531-541. https://doi.org/10.1016/j. renene.2017.02.017

Park J. and Law, K. H. (2015). Layout optimization for maximizing wind farm power production using sequential convex programming. Applied Energy 151: 320-334. https://doi. org/10.1016/j.apenergy.2015.03.139

Park, J. and Law, K.H. (2015) Layout optimization for maximizing wind farm power production using sequential convex programming. Applied Energy 151: 320-334. https://doi. org/10.1016/j.apenergy.2015.03.139

Previsic M. RE Vision Consulting, LLC, Economic methodology for the evaluation of emerging renewable technologies, October, 2011.

Saeidi D., Sedaghat A., Alamdari, P., and Alemrajabi, A.A. (2013). Aerodynamic design and economical evaluation of site specific small vertical axis wind turbines. Applied Energy 101: 765-775.https://doi.org/10.1016/j.apenergy.2012.07.047

Siano P., and Mokryani G. (2013) Assessing wind turbines placement in a distribution market environment by using particle swarm optimization. IEEE Transactions on Power Systems 28(4): 3852-3864. https://doi.org/10.1109/TPWRS.2013.2273567

Shakoor R., Hassan, M. Y., Raheem, A., and Wu, Y. K. (2016) Wake effect modeling: A review of wind farm layout optimization using Jensen- s model. Renewable and Sustainable Energy Reviews 58: 1048-1059 https://doi.org/10.1016/j. rser.2015.12.229 
Turner S.D.O., Romero D.A., Zhang P.Y., Amon C.H., and Chan, T.C.Y. (2014). A new mathematical programming approach to optimize wind farm layouts. Renewable Energy, 63: 674-680. https://doi.org/10.1016/j.renene.2013.10.023

USDE (US Department of Energy), Office of Indian Energy, Levelized Cost of Electricity, 2015, 1-9, available at: https:// www.energy.gov/sites/prod/files/2015/08/f25/LCOE.pdf [Accessed July, 2018]

Vestas, Wind turbine manufacturing company, available at: https://www.vestas.com/en/products/turbines/v100-2_0_ mw [accessed July, 2018].

Wang Y., Liu H., Long H., Zhang Z., and Yang, S. (2018) Differential evolution with a new encoding mechanism for optimizing wind farm layout. IEEE Transactions on Industrial Informatics 14(3): 1040-1054. https://doi.org/10.1109/TII.2017.2743761

Wind Resource Assessment Software, Windographer, available at: http://www.windographer.com [Accessed Dec 2019]

Wind power engineering and development, Anonymous, "How to calculate power output of wind", available at: https:// www.windpowerengineering.com/construction/calculate-wind-power-output/ [Accessed January, 2019]

Yang H., Wei Z., and Chengzhi, L. (2009) Optimal design and techno-economic analysis of a hybrid solar-wind power generation system. Applied Energy 86(2): 163-169. https://doi. org/10.1016/j.apenergy.2008.03.008

Yin P.Y., Wu T.H., and Hsu P.Y. (2017) Risk management of wind farm micro-siting using an enhanced genetic algorithm with simulation optimization. Renewable Energy 107: 508-521. https://doi.org/10.1016/j.renene.2017.02.036

Zhang P.Y., Romero D.A., Beck J.C., and Amon C.H. (2014) Solving wind farm layout optimization with mixed integer programs and constraint programs. EURO Journal on Computational Optimization, 2(3): 195-219. https://doi.org/10.1007/ s13675-014-0024-5

Zhao M., Chen, Z., and Blaabjerg, F. (2009). Optimisation of electrical system for offshore wind farms via genetic algorithm. IET Renewable Power Generation 3(2): 205-216. https://doi.org/10.1049/iet-rpg:20070112 